\title{
Attendance of men at the familial cancer clinic: what they value from the consultation
}

\author{
Elizabeth Anne Lobb, PhD, MAppSci ${ }^{1,2,3}$, Clara L. Gaff, PhD, BSc ${ }^{4,5}$, Bettina Meiser, PhD, BA ${ }^{6,7}$, \\ Phyllis N. Butow, PhD, MPH ${ }^{8}$, Rebecca Osseiran-Moisson, BA $A^{2,3}$, and Nina Hallowell, PhD, $M A^{9}$
}

\begin{abstract}
Purpose: This study examined what men from high-risk breast/ovarian cancer families valued from attending a familial cancer clinic. Methods: One hundred men from families with a BRCA1 or BRCA2 mutation completed a self-administered questionnaire. Results: Seventytwo percent $(72 \%)$ of men attended the familial cancer clinic at the request of a family member. Multivariate analyses showed that men with a preference for a collaborative decision-making style $(B=$ $-4.651,95 \% \mathrm{CI}=-9.014$ to $-0.289, P=0.04)$, those with lower levels of education $(B=-4.850,95 \% \mathrm{CI}=-9.16$ to $-0.537, P=$ 0.03 ), and those with higher levels of cancer-related anxiety (intrusion) $(B=0.920,95 \% \mathrm{CI}=0.441-1.399, P<0.001)$ were more likely to value emotional support from the clinic. Men with a collaborative decision-making style $(B=-2.68,95 \% \mathrm{CI}=-4.91$ to $-0.467, P=$ 0.02 ) were less likely, and those with higher total levels of cancerrelated anxiety (intrusion and avoidance) $(B=0.393,95 \% \mathrm{CI}=$ $0.008-0.779, P=0.04$ ) were more likely to value receiving information from the clinic. Conclusions: A preference for collaborative decision making and cancer-related anxiety predicted men valuing information and emotional support from the consultation. The finding that men's attendance is initiated by family members highlights the value men place on family responsibility. Genet Med 2009:11(6):434-440.
\end{abstract}

Key Words: BRCA1 and BRCA2, men, familial cancer clinics, attendance, preferences, values

$T_{\text {he }}$ he main emphasis in genetic counseling and testing for hereditary breast/ovarian cancer is on female family members. In both sexes, germline BRCA1/2 mutations have been associated with elevated risks for cancers at multiple organ sites, including pancreas, stomach, gall bladder, and bile duct, as well as cutaneous and ocular melanoma. ${ }^{1,2}$

The estimated cumulative lifetime risk for breast cancer in men with BRCA2 mutations is $6.9 \% .^{3-5}$ Male BRCA2 carriers

From the ${ }^{1}$ Calvary Health Care Sydney, Department of Palliative Care, Kogarah, New South Wales, Australia; ${ }^{2}$ WA Centre for Cancer and Palliative Care, Curtin University of Technology, Bentley, Western Australia; ${ }^{3}$ School of Nursing, Midwifery and Post-graduate Medicine, Edith Cowan University, Perth, Western Australia; ${ }^{4}$ Genetic Health Services Victoria, Parkville, Victoria, Australia; ${ }^{5}$ Murdoch Children's Research Institute, Parkville, Victoria, Australia; ${ }^{6}$ Psychosocial Research Group, Prince of Wales Hospital, Sydney, New South Wales, Australia; ${ }^{7}$ Prince of Wales Clinical School, University of New South Wales, New South Wales, Australia; ${ }^{8}$ Centre for Medical Psychology and Evidence-based Decision Making, University of Sydney, New South Wales, Australia; ${ }^{9}$ Centre for Population Health Sciences, University of Edinburgh, Edinburgh, Scotland.

Elizabeth Anne Lobb, PhD, MAppSci, Calvary Health Care Sydney, Kogarah, New South Wales 2117, Australia. E-mail: Liz.Lobb@sesiahs. health.nsw.gov.au.

Disclosure: The authors declare no conflict of interest.

Submitted for publication December 18, 2008

Accepted for publication February 18, 2009.

Published online ahead of print April 2, 2009

DOI: 10.1097/GIM.0b013e3181a18982 have an estimated lifetime risk of prostate cancer of between 6 and $14 \% .^{6-8}$

As the major risks conferred by mutations in $B R C A 1$ and $B R C A 2$ are related to cancer of the breast, ovary, fallopian tubes, and peritoneum, predictive testing among men is mainly offered by genetic services to clarify risks for other family members, particularly daughters. ${ }^{9,10}$ This stance is supported by data suggesting that men do not believe that just knowing their mutation status is a sufficient motivation to have genetic testing. ${ }^{11}$ They are motivated to seek genetic counseling and testing by concern for their daughters ${ }^{11,12}$ and also may want to know their carrier status as a way of fostering family solidarity and supporting others through the process. ${ }^{11}$

However, fewer men than women come forward for predictive $B R C A 1 / 2$ testing ${ }^{13-16}$ and men who do take up genetic counseling have a tendency to miss appointments, drop out of testing protocols ${ }^{17,18}$ and experience difficulties in establishing appropriate posttest care. ${ }^{12}$ Misinformation may be a barrier to attendance. ${ }^{19}$ Women at risk because of a paternal family history of breast cancer are underrepresented in familial cancer clinics, ${ }^{20}$ suggesting that families and health professionals may assume that risk cannot be transmitted by men because breast cancer largely affects women. Men may also hold a less positive attitude to addressing health issues in general and attending for genetic counseling or testing specifically. ${ }^{10}$

Nonetheless, studies report that men in families with hereditary breast/ovarian cancer fear they will develop breast cancer, are aware that they are at increased risk of prostate and bowel cancer, and have intrusive thoughts about this increased risk. ${ }^{10,12,17}$ It has also been reported that men admit to preferring avoidance and denial to cope with their cancer risk, ${ }^{9,10}$ avoid discussing their emotions, ${ }^{10,17}$ have unresolved grief about past and future losses, and experience guilt about passing on a potentially lethal gene mutation to their future offspring, ${ }^{17,21-23}$

There is a dearth of data to enable the provision of genetic services that meet men's individual needs, particularly in the absence of a high medical risk. Data are needed specifically on men's motivations for attending a specialist cancer genetics service (as distinct from deciding to have genetic testing), who they communicate with, and what they value from the consultation, and the predictors of these attitudes. To address this, we studied men from families known to have a BRCA1 or BRCA2 mutation who attended a familial cancer service.

\section{Hypotheses}

On the basis of the literature on women, we hypothesized that when measured retrospectively, valuing emotional and/or informational support would be associated with younger age, higher educational level, the number of biological daughters and sons, professional occupation, higher cancer-related anxiety (intrusive thoughts and avoidance) and the number of relatives who had died or been diagnosed with breast cancer (cancer burden). 


\section{MATERIALS AND METHODS}

\section{Sample}

Men from families with a known $B R C A 1$ or $B R C A 2$ mutation and who were $18-80$ years of age, not suffering from a mental illness, and could read English proficiently were invited to join the study. Men who were at low risk, and who had a diagnosis of cancer were excluded.

\section{Procedure}

Participants were recruited through the Kathleen Cuningham Consortium into Familial Breast Cancer (kConFab), a database of high-risk breast cancer families. kConFab is an Australian study established to coordinate the collection of genetic, epidemiological, and clinical data in Australian families with a dominantly inherited susceptibility to breast cancer. ${ }^{24}$ All kConFab participants who were eligible for the current study were sent a letter inviting them to participate. An opt-out card was included with a reply paid envelope for those who did not wish to participate or be contacted regarding this study. If the opt-out card was not received within 2 weeks, a self-report questionnaire was mailed with an information sheet and consent form with a stamped addressed envelope for return. If the questionnaire was not returned within 2 weeks, a reminder letter and a second questionnaire was mailed. Ethics approval was obtained from 17 institutional human research ethics committees.

\section{Data collection and measures}

The questionnaire included both previously validated and new purposively designed items. All questionnaires were given a code and only this code appeared on the database. To protect the confidentiality and anonymity of study participants, the list of names and addresses of participants was kept in a locked filing cabinet, separate to the coding list. Any computers used for analysis were password protected. Research data was stored on a computer and paper documents filed for the required time. After this time, all irrelevant material will be disposed of by shredding and erasure of computer-generated data. Only the chief investigators had access to the data.

\section{Demographic characteristics}

Age, educational level, marital status, occupation, and the number and gender of biological children were assessed.

\section{Information preference style}

This scale assesses information preference style and is based on a measure adapted from the Cassileth Information Styles Questionnaire. ${ }^{25}$ Participants are asked to indicate whether they want (i) only information needed to deal with the immediate issues related to their own chance of developing cancer or their family's chance of developing cancer; (ii) additional information only if it is good news; or (iii) as much information as possible, good or bad.

\section{Decision-making preference style}

This item assesses participants' preferences for participation in making decisions about treatment. ${ }^{26}$ Participants are asked to indicate whether they prefer (i) a passive role in decision making (e.g., "I would like the genetics cancer specialist to make the decision [about genetic testing or screening] using all that is known about breast cancer genetics"); or (ii) a transitional role between passive and collaborative (e.g., I would like the genetics cancer specialist to make the decisions after considering my needs and opinions); (iii) a collaborative role (e.g., I would like the genetics cancer specialist and I to make the decisions together); or (iv) an active role (e.g., I would like to make the decision using all I know or have learnt about breast cancer genetics or I would like to make the decision, after considering the specialist's opinion). Although the decisionmaking styles were conceptualized as being on a continuum, for analysis purposes the preference styles were collapsed into passive, collaborative, or individual.

\section{Valued components of genetic counseling}

This section was prefaced by the statement: "Different men go to the familial cancer clinic wanting different things from their appointment," and "we are interested in knowing what was important to you when you attended the genetic clinic," and men were asked to indicate on a six-point Likert-type scale ranging from "not at all important" to "very important" their response to 15 possible reasons for attending a genetic clinic (Table 1). This scale was developed as part of previous studies in women from high-risk breast cancer studies and included items suggested by expert opinion, the literature, and structured telephone interviews with men. ${ }^{27,28}$

\section{Cancer burden}

Three items assessed the number of family members diagnosed with breast/ovarian cancer, their year of diagnosis (or

Table 1 What men valued from the familial cancer clinic $(n=100)$

\begin{tabular}{|c|c|}
\hline & $\begin{array}{l}\text { Percent considered } \\
\text { important }\end{array}$ \\
\hline $\begin{array}{l}\text { Provide information about the breast cancer } \\
\text { in the family }\end{array}$ & 98 \\
\hline Provide information about cancer genes & 97 \\
\hline $\begin{array}{l}\text { Tell me about my daughter's chance of } \\
\text { developing cancer }\end{array}$ & 90 \\
\hline $\begin{array}{l}\text { Tell me about my chance of developing } \\
\text { cancer }\end{array}$ & 87 \\
\hline $\begin{array}{l}\text { Talk about benefits and limitations of having } \\
\text { a gene test }\end{array}$ & 85 \\
\hline $\begin{array}{l}\text { Inform me of specific options for cancer } \\
\text { prevention }\end{array}$ & 83 \\
\hline $\begin{array}{l}\text { Tell me what I should do for cancer } \\
\text { screening }\end{array}$ & 83 \\
\hline $\begin{array}{l}\text { Tell me about my son's chance of } \\
\text { developing cancer }\end{array}$ & 80 \\
\hline $\begin{array}{l}\text { Help me cope if I have a test and it shows } \\
\text { that I carry a genetic fault }\end{array}$ & 79 \\
\hline $\begin{array}{l}\text { Help me decide whether or not to have gene } \\
\text { testing }\end{array}$ & 69 \\
\hline $\begin{array}{l}\text { Talk about how it feels to have cancer in } \\
\text { the family }\end{array}$ & 67 \\
\hline $\begin{array}{l}\text { Help me come to terms with my own } \\
\text { chance of developing cancer }\end{array}$ & 64 \\
\hline Help me feel less anxious about cancer & 58 \\
\hline Help me face my fears about cancer & 58 \\
\hline $\begin{array}{l}\text { Provide me with emotional support to cope } \\
\text { with my situation }\end{array}$ & 49 \\
\hline
\end{tabular}


death if applicable) and their age at the time of diagnosis or death. ${ }^{19,28,29}$

\section{Cancer-related anxiety}

This was measured using the Impact of Events Scale, a 15-item validated scale measuring intrusive and avoidance thoughts in relation to a specific stressor. ${ }^{30}$ In the current study, the particular stressor was concern about being at risk of developing cancer and about family members developing cancer. In a previous validation study of women with a family history of breast cancer, the intrusion and the avoidance subscales have been found to be highly consistent with Cronbach's coefficient alpha of 0.84 and 0.91 , and a test-retest reliability of $r=0.75$ and 0.78 , respectively. ${ }^{31}$ Scores above 20 on either scale indicate a significant stress response. ${ }^{32}$

\section{Attending the familial cancer clinic}

The participants were asked four specific questions about their attendance at a familial cancer clinic. Men were asked whose idea it was to go to the clinic; who they told they were attending the clinic; if they had attended the consultation on their own, and if not, with whom had they attended.

\section{Statistical analysis}

Tests of association between (a) demographics (age, educational level, marital status, occupation, and the number and gender of biological children) and (b) levels of cancer-related anxiety (intrusive thoughts and avoidance) were carried out using $\chi^{2}$ tests and Fisher's Exact tests for categorical variables, $t$ tests and analysis of variance for normally distributed continuous variables, and Mann-Whitney and Kruskal-Wallis tests for ordinal or nonnormally distributed continuous variables. Factor analyses were conducted on the 15 items scale of what men who attended the familial cancer clinic valued from the consultation. The Principal Component Analysis with Equamax rotation provided the clearest results to interpret. All variables with a bivariate association with $P<0.25$ were then entered into a linear regression model and progressively eliminated until the only remaining variables were those with $P<0.05$, or those which confounded the association of interest. ${ }^{33}$

\section{RESULTS}

\section{Response rates}

Four hundred and seventy-nine men from families with a known BRCA1 or BRCA2 mutation were approached through the kConFab National Database in December 2005. Two hundred and twenty-six questionnaires were returned (44\% response rate), and of these, 100 (44\%) men had attended a familial cancer clinic and formed the sample for these analyses. Comparisons of men who attended and did not attend Familial Cancer Clinics will be reported elsewhere.

Table 2 shows the sociodemographic characteristics of the sample. The mean age of participants was 57 (SD 12.4, range $27-83)$. The majority of men were married (84\%). Less than half $(43 \%)$ were in full-time employment and approximately one third were retired $(27 \%)$. More than half were in professional employment (56\%). Forty-nine percent reported they had received genetic testing.

Men reported a cancer burden of, on average, two family members who had been diagnosed with breast or ovarian cancer and were still alive (median 2.0, SD 0.94, range 1-5) and two family members who had died of breast/ovarian cancer (median 2.0, SD 1.5, range 1-8). Univariate analyses showed a statisti-
Table 2 Demographic characteristics of sample $(n=100)$

\begin{tabular}{|c|c|}
\hline Age & Median 57 (SD 12.5, range 27-83) \\
\hline \multicolumn{2}{|l|}{ Marital status } \\
\hline Married & $84 \%$ \\
\hline Not married & $16 \%$ \\
\hline \multicolumn{2}{|l|}{ Educational level } \\
\hline Below year 12 & $42 \%$ \\
\hline Above year 12 & $58 \%$ \\
\hline \multicolumn{2}{|l|}{ Employment } \\
\hline Full time & $43 \%$ \\
\hline Part time & $11 \%$ \\
\hline Unemployed & $1 \%$ \\
\hline Self-employed & $9 \%$ \\
\hline Retired & $27 \%$ \\
\hline Other & $8 \%$ \\
\hline \multicolumn{2}{|l|}{ Occupation } \\
\hline Professionals & $56 \%$ \\
\hline Nonprofessional & $43 \%$ \\
\hline \multicolumn{2}{|l|}{ Children } \\
\hline Yes & $89 \%$ \\
\hline Sons & $67 \%$ (med. 1, SD 0.92, range $1-5)$ \\
\hline Daughters & $73 \%$ (med. 1, SD 1.09 , range $1-5)$ \\
\hline No & $11 \%$ \\
\hline
\end{tabular}

cal difference between men who had no relatives who had died and men who had 1 or more relatives who had died and cancer-related anxiety (intrusion and avoidance) $\left(\chi^{2}=17.4\right.$, $P<0.001)$; however, this was not significant in the multivariate analyses.

The majority of men did not show significant levels of cancer-related anxiety. Five men scored above the clinical cutoff score of 20 for both the intrusion subscale (median score 9.5, SD 4.40, range 6-27) and the avoidance subscale (median score 11.0, SD 5.3, range 8-29). Five men scored above the clinical cut-off for the avoidance subscale only. Both scales demonstrated high estimates of internal consistency (Cronbach's alpha values of 0.90 and 0.89 , respectively). The median total score for cancer-related anxiety was 23.6 (SD 9.2, range 15-53).

\section{Provision of clinical services and preferences}

The majority of men reported that they did not initiate attendance at the familial cancer clinic themselves and that it was at the suggestion of a family member (72\%). Thirteen percent $(13 \%)$ indicated that it was the idea of their partner/ spouse/biological mother of their children. Eight percent $(8 \%)$ said that their attendance was at the suggestion of their General Practitioner and $6 \%$ a specialist doctor. Nine percent $(9 \%)$ reported that they had attended at their own initiation and $6 \%$ reported that they had received a letter from a familial cancer 
clinic. Participants indicated more than one source; hence, the total number of responses exceeded $100 \%$.

The majority of men $(87 \%)$ reported that they told their spouse/partner they were attending the clinic, 33\% told their sons, $42 \%$ informed their daughters, and $23 \%$ their mothers. Around half said they went to the clinic on their own (46\%). Of the remainder, $40 \%$ went with their partner/spouse, 5\% with a daughter, and $5 \%$ with their mother. Fewer than $3 \%$ went with a son, a brother or a father. Participants could indicate more than one answer; hence, responses are $>100 \%$.

The majority of men reported that they wanted to receive all information relating to their own chance of developing cancer or their family's chance of developing cancer, regardless of whether it was good or bad $(70 \%)$. One third $(30 \%)$ stated that they wanted information that only dealt with immediate issues. Six percent $(6 \%)$ of men wanted the genetics specialist to make medical decisions on issues such as genetic testing or screening; $29 \%$ wanted to make the decision themselves after a specialist opinion; $43 \%$ wanted a collaborative decision-making process between the genetics specialist and themselves; and 19\% wanted to make the decisions themselves.

To determine what men valued from their attendance at the familial cancer clinic, a factor analysis was conducted on the 15 items (with the full range of scores) with Equamax rotation. The solution produced three distinct and coherent factors explaining $71 \%$ of the variance. The weightings and details on factor loading on each factor are shown in Table 3. The first factor contained items related to Emotional Support, the second factor related to Cancer Information, and the third factor to Family Concerns. The reliability of the factors was measured using Cronbach's alpha and proved good to moderate internal consistency-Factor 1 Emotional Support $\alpha=0.96$, Factor 2 Cancer
Information $\alpha=0.96$, and Factor 3 Family Concerns $\alpha=0.49$. None of the factors were normally distributed; therefore, further analysis was undertaken using nonparametric tests (MannWhitney and Kruskal Wallis) analysis of variance.

\section{Factors associated with valued attributes of familial cancer clinics}

\section{Emotional support}

Multivariate analyses showed that men with a preference for a collaborative decision-making style $(B=-4.651,95 \% \mathrm{CI}=$ -9.014 to $-0.289, P=0.04$ ) (mean 23.5 vs. 20.1 , SD 11.2; range $0-35)$, those with lower levels of education $(B=-4.850$, $95 \% \mathrm{CI}=-9.16$ to $-0.537, P=0.03$ ) (mean 24.1 vs. 18.0 ), and those with higher levels of cancer- related anxiety (intrusion) $(B=0.920,95 \% \mathrm{CI}=0.441-1.399, P=<0.001)$ (mean score 24.6 vs. 16.6 ) were more likely to value receiving emotional support from the clinic more highly.

\section{Cancer information}

Men with a collaborative decision-making style $(B=-2.68$, $95 \% \mathrm{CI}=-4.91$ to $-0.467, P=0.02)$ (19.1 vs. 20.10 SD 5.13; range 4-25) were less likely to value receiving information and those with higher total levels of cancer-related anxiety (intrusion and avoidance) $(B=0.393,95 \% \mathrm{CI}=0.008-0.779, P=$ 0.04 ) (mean score 24.1 vs. 19.8) were more likely to value receiving information from the clinic more highly.

\section{Family concerns}

Men with sons $(B=2.72,95 \% \mathrm{CI}=1.13-4.53, P=0.001)$ (mean 12.9 vs. 10.4; SD 0.38; range 3-15) and higher total levels of cancer-related anxiety (intrusion and avoidance) ( $B=$

Table 3 Factor analysis rotated component matrix, principal component analysis with equamax rotation

\begin{tabular}{llll}
\hline Factor 3 \\
\hline
\end{tabular}

Factor 1: Emotional support

Help me come to terms with my own chance of developing cancer 0.877

Help me face my fears about cancer

Help me decide whether to have a genetic test 0.866

Help me feel less anxious about cancer 0.846

Provide me with emotional support to cope with my situation

Help me cope if I have a test and it shows that I carry a genetic fault

Factor 2: Cancer information

Inform me of specific options for cancer prevention

Tell me what I should do for screening

Talk about benefits and limitations of having a gene test

Tell me about my chance of developing cancer

Provide me with information on cancer genes

Factor 3: Family concerns 
$0.114,95 \% \mathrm{CI}=0.046-0.183, P=<0.001)$ (mean score 14.6 vs. 12.1) were more likely to value receiving specific information about family concerns more highly.

\section{DISCUSSION}

Understanding the experiences of men in $B R C A 1$ and $B R C A 2$ families is limited by the few studies addressing this issue and small sample sizes. This retrospective, descriptive Australian study is the first quantitative study to our knowledge to examine men's attendance for genetic counseling before genetic testing in a large sample of men from families with a known BRCA1/ $B R C A 2$ mutation. The majority of studies to data have examined men's experiences of genetic testing, in particular family communication around the dissemination of testing results. Our study provides data to enable the provision of genetic services that meet men's individual needs, specifically their information and decision-making preferences, their reasons for attending a specialist cancer genetics service (as distinct from deciding to have genetic testing), who they communicated with about the appointment and what they valued from the consultation.

\section{Attending the familial cancer clinic}

We found that for most men men's attendance at the familial cancer clinic had not been at their own initiative but had been prompted by a female family member. This finding may reflect the family's participation in the Kathleen Cuningham Consortium into Familial Breast Cancer (kConFab) database of highrisk breast cancer families, which notifies families on their database when a predisposition mutation is located in a family member. Although the high proportion informed in this way may not be generalized, nonetheless, it does indicate that at least some families are motivated to inform and encourage their male relatives to access genetic services. Fourteen percent (14\%) of men said that their attendance was at the suggestion of a doctor (GP or Medical Specialist). This is in contrast to our study on women from high-risk breast cancer families, where $62 \%$ of unaffected women were referred to the familial cancer clinic by either their general practitioner or medical specialist. ${ }^{28}$ These differences may reflect different recruitment sources as women were recruited from clinics directly, and the men described here were recruited through a research database. Therefore, we cannot assume attendance by men at familial cancer clinics is influenced by biased referral practices of General Practitioners or an assumption that risk cannot be transmitted by men. However, these results do suggest that the most effective way of addressing the underrepresentation of men in familial cancer genetics clinics may be by health professionals ensuring female relatives attending clinics are aware of the need to convey information to male family members. This is particularly pertinent as previous studies have reported that men are often excluded from family conversations about hereditary breast and ovarian cancer. ${ }^{10,34}$ On the other hand, concern has been expressed that pressure from a partner or other family members may constitute coercion. ${ }^{12,35}$ Our finding that $72 \%$ of men attended genetic counseling at the request of a family member may add further weight to these concerns; however, this may be attenuated by the finding that around half the men (46\%) attended the familial cancer clinic on their own.

Several studies have reported a sense of responsibility among both men and women to share genetic testing results for breast/ ovarian cancer with their families. ${ }^{12,21,36}$ Although men in our study were selective about informing family members that they planned to attend a clinic, the majority of men (87\%) reported that they went on to have genetic testing and shared their test result with other family members. This finding is similar to that reported by Liede et al., ${ }^{12}$ who reported that the great majority of men in their study discussed their genetic-test result with a family member. It is also consistent with Hallowell's findings that both male carriers and their partners perceive themselves, rather than health professionals, responsible for disclosing information about genetic testing and genetic risk to their children. ${ }^{35}$

\section{Men's information and decision-making preferences}

The majority of men in this study reported that they wanted to receive all information relating to their own chance of developing cancer or their family's chance of developing cancer, regardless of whether it was good or bad news (70\%). It may be anticipated that families who are enrolled on the $\mathrm{kConFab}$ database have a higher level of awareness of their genetic risk and access to genetic information that may not be readily available to the broader high-risk community. These findings are in contrast to those of Gaff et al., ${ }^{37}$ where $34 \%$ of men with a family history of prostate cancer reported that they only wanted to receive good information. However, we framed our question differently asking whether men wanted to receive all information good or bad, whereas Gaff et al. asked whether men wished to receive good or bad information. Our findings are similar to the information preferences reported in our previous study of women, where $89 \%$ of them reported wanting to receive all information good or bad (compared with $70 \%$ of the men in this study). We also found that one third of men $(30 \%)$ stated that they wanted information that only dealt with immediate issues, compared with $10 \%$ of unaffected women. ${ }^{28}$ As previously discussed, the presence of a BRCA1 or BRCA2 mutation does not have comparable long-term health implications in men and women. Specifically for women, a future screening program for breast/ovarian cancer is one of the key components of their cancer genetic consultation.

Less than half of the men wanted a collaborative decisionmaking process around genetic testing (43\%), 19\% of men wanted an active role (i.e., to make the decision themselves), and $29 \%$ wanted a passive role. This is in contrast to our study of women, where $86 \%$ of unaffected women wanted collaborative decision making and only $10 \%$ of unaffected women preferred an active role in decision making. Again, this may reflect the different contexts of these two studies: men in this study were from families with a known $B R C A$ mutation, whereas women in our previous study were attending for family history assessment. Men attending for testing for a known cancer predisposition mutation may feel there was no decision to be made. The finding that approximately one third of men preferred a passive role in decision making may also be explained by findings from a previous Australian study that found that men tended to distance themselves by constructing a fatalistic or deterministic explanation of inheritance. ${ }^{23}$ Differences between the findings of this study and our previous studies on women may also be because the women were recruited from familial cancer clinics and were asked their preferences before their consultation, whereas the men in this current study were asked retrospectively.

\section{What men valued from the familial cancer clinic}

Contrary to our hypotheses, our results showed that age, occupation, the number of biological daughters, and cancer burden were unrelated to what men valued from the familial cancer clinic. The vast majority of men valued receiving information about cancer genetics, prevention, surveillance, and risk information for themselves and for their children. In addition, 
they also valued receiving emotional support. These results are similar to those reported in our previous study of the expectations of women from high-risk breast cancer, ${ }^{28}$ to other studies in women from high-risk breast cancer families, ${ }^{38,39}$ and two studies of men at high risk for prostate cancer. ${ }^{37,40}$

In line with our hypotheses, higher levels of cancer-related anxiety (intrusion and avoidance) predicted a higher value placed by men on receiving both information and emotional support. However, it should be noted that the cancer-related anxiety levels in these men were not high, with less than a dozen men scoring above the clinically significant cut-off. These data are in contrast to the findings of McAllister et al. ${ }^{10}$ and supports the findings of Lodder et al. ${ }^{9}$ who concluded that the majority of men at risk did not report using avoidance to reduce their levels of distress.

Forty-two percent ( $42 \%$ ) of our sample were educated below year 12. Lower levels of education were associated with valuing emotional support and men with sons valued receiving information specific to family concerns. As these data were collected retrospectively, it may be that men were originally unaware that their sons could inherit a predisposition to breast cancer from them and valued receiving this information in the consultation.

\section{Limitations of the study}

Although our findings are contrary to our hypotheses and previous studies, in univariate analyses significant differences were found between cancer burden and cancer-related anxiety with men who had a greater number of relatives, who had died of breast/ovarian cancer showing higher levels of cancer-related anxiety than men, who had no relatives who had died. A larger sample size may have produced significant results in the multivariate analyses.

The majority of men reported that they had had daughters (73\%); hence, this subset of men was too small to allow statistically meaningful comparisons with those who did not have daughters. The mutation status of the children of these men was not available to the researchers. Perhaps, the levels of anxiety or the preferences of men who had mutation positive daughters or sons may have been different, although as we reported, men's levels of distress were not at clinical levels in this study.

\section{CONCLUSIONS}

This is the first quantitative study involving a large sample of men from high-risk breast cancer families, with a known mutation, who had attended a familial cancer clinic, to assess what they value from that encounter. In a recent review of studies of men from high-risk breast and/or ovarian cancer families, Daly ${ }^{41}$ drew attention to "the socially and culturally bound gender roles which affect the patterns of family dynamics and the way men and women understand and respond to health threats." She suggests that "these complex dynamics have practical implications for genetic health care providers." ${ }^{4}$

Our findings that most men in this study did not attend the familial cancer clinic at their own initiation, that they prefer receiving all information both good and bad news, and that higher levels of cancer-related anxiety predicted them valuing information and emotional support more, give some further direction for future practice.

As the majority of men reported that they attended at the request of a female family member, we recommend that healthrelated messages within $B R C A 1 / 2$ families may be effectively directed through the female members of these families to reach the at-risk men. Our findings also highlight the importance of tailoring the consultation to the individual. Specifically, al- though the majority of men preferred to receive all information, one third only wanted to receive information on immediate issues. In addition, we found variability in decision-making style, so it is important to ascertain men's preferences in the consultation.

The observation in previous studies that men employ avoidance coping strategies was not supported in our study. However, although the levels of cancer-related anxiety in this study were not clinically significant, familial cancer practitioners need to take the time to ascertain how anxious men are, as higher level of distress did predict men placing a higher value on receiving information and emotional support. Providing men with written information before attending may alleviate some of their cancer-related anxiety and help them to prepare for their genetic counseling session. ${ }^{42}$ The retrospective reporting by men of these data and the recruitment of men from an existing database of high-risk familial breast/cancer families necessitates caution in translating these findings to the broader group of men who attend the familial cancer clinic. Hence, there may be an underestimation by counselors of men's psychological distress among this broader group. This highlights the importance of paying attention to men's psychosocial issues as a critical component of effective cancer genetic counseling, which aims to "help derive personal meaning from cancer genetic information and empower (individuals) to make educated informed decisions" and to educate. ${ }^{43}$

In conclusion, an appreciation by counselors of the role of social dynamics and perceived moral obligations within the family and their impact on decisions made by men regarding genetic testing is likely to improve the counseling process. ${ }^{35}$ Being aware of men's sense of familial obligation can allow counselors to discuss the personal implications of the family history and balance the information given about genetic testing without any perceived coercion. ${ }^{41}$

\section{ACKNOWLEDGMENTS}

A/Prof. Elizabeth Lobb was supported by a National Health and Medical Research Council of Australia, Australian Clinical Research Fellowship 222915. A/Professor Bettina Meiser was supported by a National Health and Medical Research Council (NHMRC) of Australia Public Health Fellowship no. 007079. Professor Phyllis Butow was supported by an NHMRC Principal Research Fellowship. Data collection for this study is supported by the Kathleen Cuningham Foundation Consortium into Familial Cancer Research (kConFab). The authors thank the men who participated in this research.

\section{REFERENCES}

1. Moslehi R, Chu W, Karlan B, et al. BRCA1 and BRCA2 mutation analysis of 208 Ashkenazi Jewish women with ovarian cancer. Am J Hum Genet 2000; $66: 1259-1272$

2. Struewing JP, Hartge $\mathrm{P}$, Wacholder S, et al. The risk of cancer associated with specific mutations of BRCA1 and BRCA2 among Ashkenazi Jews. $N$ Engl J Med 1997;336:1401-1408.

3. Thompson D, Easton D. Variation in cancer risks, by mutation position, in BRCA2 mutation carriers. Am J Hum Genet 2001;68:410-419.

4. Thompson D, Easton D. Cancer incidence in BRCA1 mutation carriers. JNCI 2002;94:1358-1365.

5. Tai YC, Domchek SM, Parmigiani G, Chen S. Breast cancer risk among male BRCA1 and BRCA2 mutation carriers. JNCI 2007;99:1811-1814.

6. Easton D, Steele L, Fields R. Cancer risks in two large breast cancer families linked to BRCA2 on chromosome 13q12-13. Am J Hum Genet 1997;61:120128.

7. Edwards SM, Kote-Jarai Z, Meitz J, et al. Two percent of men with earlyonset prostate cancer harbor germline mutations in the BRCA2 gene. Am $J$ Hum Genet 2003;72:1-12

8. Liede A, Karlan BY, Narod SA. Cancer risks for male carriers of germline mutations in BRCA1 or BRCA2: a review of the literature. J Clin Oncol $2004 ; 22: 735-742$ 
9. Lodder L, Frets PG, Trijsburg RW, et al. Men at risk of being a mutation carrier for hereditary breast/ovarian cancer: an exploration of attitudes and psychological functioning during genetic testing. Eur J Hum Genet 2001;9:492-500.

10. McAllister MF, Evans DGR, Ormiston W, Daly P. Men in breast cancer families: a preliminary qualitative study. J Med Genet 1998;35:739-744.

11. Daly PA, Nolan C, Green A, et al. Predictive testing for BRCA1 and 2 mutations: a male contribution. Annals of Onc 2003;14:549-53.

12. Liede A, Metcalfe K, Hanna D, et al. Evaluation of the needs of male carriers of mutations in BRCA1 or BRCA2 who have undergone genetic counseling. Am J Hum Genet 2000;67:1494-504.

13. Wonderling D, Hopwood P, Cull A, Douglas F. A descriptive study of UK cancer genetics services: an emerging clinical response to the new genetics. BJC 2001;85:166-70.

14. Fraser L, Bramald S, Chapman C, et al. What motivates interest in attending a familial cancer genetics clinic. Fam Cancer 2003;2:159-168.

15. Hallowell N, Ardern-Jones A, Eeles R, et al. Men's decision-making about predictive BRCA1/2 testing: the role of family. J Genet Couns 2005;14:207-217.

16. Finlay E, Stopfer JE, Burlingame E, et al. Factors determining dissemination of results and uptake of genetic testing in families with known BRCA1/2 mutations. Genet Test 2008;12:81-91.

17. Dudok de Wit AC, Tibben A, Frets PG, et al. Males at-risk for the BRCA1gene, the psychological impact. Psych Onc 1996;5:251-257.

18. Foster C, Evans DGR, Eeeles R, et al. Predictive testing for BRCA1/2 attributes, risk perception and management in a multi-centre clinical cohort. BJC 2002;86:1209-1216.

19. Watson M, Lloyd SM, Eeles R, et al. Psychosocial impact of testing (by linkage) for the BRCA1 breast cancer gene: an investigation of two families in the research setting. Psych Onc 1996;5:233-239.

20. Green J, Richards M, Murton F, et al. Family communication and genetic counseling: the case of hereditary breast and ovarian cancer. J Genet Couns 1997;6:45-60.

21. d'Agincourt-Canning L. Experiences of genetic risk: disclosure and the gendering of responsibility. Bioethics 2001;15:231-247.

22. Lynch HT, Snyder C, Lynch JF, et al. Patient responses to the disclosure of BRCA mutation tests in hereditary breast-ovarian cancer families. Cancer Genet Cytogenet 2006;165:91-97.

23. Hallowell N, Ardern-Jones A, Eeles R, et al. Guilt, blame and responsibility: men's understanding of their role in the transmission of BRCA1/2 mutations within their family. Sociol Health Illn 2006;28:969-988.

24. Osborne R, Hopper JL, Kirk J, Chenevix-Trench G. A resource for studies into the genetics, epidemiology, biology, pathology and psychosocial aspects of breast cancer families. Identification and characterisation of eligible families. Med J Aust 2000;172:463-464.

25. Cassileth BR, Zupkis RV, Sutton-Smith K, March V. Information and participation preferences among cancer patients. Ann Intern Med 1980;92:832-836.

26. Degner LF, Sloan J. Decision making during serious illness: what role do patients really want to play? J Clin Epi 1992;45:300-303.
27. Lobb EA, Butow P, Meiser B, et al. Women's preferences and consultants' communication of risk in consultations about familial breast cancer: impact on patient outcomes. J Med Genet 2003;40:e56.

28. Lobb EA, Butow P, Meiser B, et al. Tailoring communication in consultations with women from high risk breast cancer families. BJC 2002;87:502-508.

29. Meiser B, Butow PN, Barratt A, et al. Attitudes to genetic testing for breast cancer susceptibility in women at increased risk of hereditary breast cancer. J Med Genet 2000;37:472-476.

30. Horowitz M, Wilner N, Alvarez W. Impact of Events Scale: a measure of subjective stress. Psychosom Med 1979;41:209-218.

31. Thewes B, Meiser B, Hickie I. Validation of the Impact of Events Scale in women at increased risk of developing hereditary breast cancer. Psych Onc 2001;10:459-468

32. Cella DF, Mahon SM, Donovan M. Cancer recurrence as a traumatic event. Behav Med 1990;16:15-22.

33. Hosmer DW, Lemeshoe S. Applied logistic regression. Brisbane: Wiley, 1989

34. Patenaude AF, Dorval M, DiGianni LS, Schneider KA, Chittenden A, Garber JE. Sharing BRCA1/2 test results with first-degree relatives: factors predicting who women tell Journal of Clinical Oncology. J Clin Onc 2006;24:700-706.

35. Hallowell N, Ardern-Jones A, Eeles R, et al. Communication about genetic testing in families of male BRCA1/2 carriers and non-carriers: patterns, priorities and problems. Clin Genet 2005;67:492-502

36. Julian-Reynier C, Eisinger F, Chabal F, et al. Disclosure to the family of breast/ovarian cancer genetic test results: patient's willingness and associated factors. Am J Med Genet 2000;94:13-18.

37. Gaff CL, Cowan R, Meiser B, Lindeman G. Genetic services for men: the preferences of men with a family history of prostate cancer. Genet Med 2006;8:771-778.

38. Julian-Reynier C, Eisinger F, Chabal F. Cancer genetics clinics: target populations and consultees' expectations. Eur J Cancer Prev 1996;32A:398403.

39. Julian-Reynier C, Eisinger F, Chabal F, et al. Cancer genetic clinics: why do women who already have had cancer attend. Eur J Cancer Prev 1998;34: $1549-1553$.

40. Wakefield CE, Meiser B, Gaff CL, et al. A multidisciplinary overview of the issues faced by unaffected men with a family history of prostate cancer. J Urol 2008;80:38-44. Impact Factor 3.95.

41. Daly MB. The impact of social roles on the experiences of men in BRCA1/2 families: implications for counseling. $J$ Genet Coun 2009;18:42-48.

42. Hallowell N, Murton F, Statham H, et al. Women's need for information before attending genetic counselling for familial breast or ovarian cancer: a questionnaire, interview and observational study. BMJ 1997;314:281-282.

43. Trepanier A, Ahrens M, McKinnon W, et al. Genetic cancer risk assessment and counseling: recommendations of the National Society of Genetic Counselors. J Genet Couns 2004;13:83-114. 